Please do not remove this page

RMIT

UNIVERSITY

\title{
Disciplining writing: The case for multi-disciplinary writing groups to support writing for publication by higher degree by research candidates in the humanities, arts and social sciences
}

Cuthbert, Denise; Spark, Ceridwen; Burke, Eliza

https://researchrepository.rmit.edu.au/esploro/outputs/9921858159901341/filesAndLinks?institution=61RMIT_INST\&index=null

Cuthbert, D., Spark, C., \& Burke, E. (2009). Disciplining writing: The case for multi-disciplinary writing groups to support writing for publication by higher degree by research candidates in the humanities, arts and social sciences. Higher Education Research and Development, 28(2), 139-149.

https://doi.org/10.1080/07294360902725025

Document Version: Accepted Manuscript

Published Version: https://doi.org/10.1080/07294360902725025

Repository homepage: https://researchrepository.rmit.edu.au

(C) 2009 Routledge

Downloaded On 2023/04/26 18:41:56 +1000 
Thank you for downloading this document from the RMIT Research Repository.

The RMIT Research Repository is an open access database showcasing the research outputs of RMIT University researchers.

RMIT Research Repository: http://researchbank.rmit.edu.au/

\section{Citation:}

Cuthbert, D, Spark, C and Burke, E 2009, 'Disciplining writing: The case for multi-disciplinary writing groups to support writing for publication by higher degree by research candidates in the humanities, arts and social sciences', Higher Education Research and Development, vol. 28, no. 2, pp. 139-149.

See this record in the RMIT Research Repository at:

http://researchbank.rmit.edu.au/view/rmit:15846

Version: Accepted Manuscript

Copyright Statement: (c) 2009 Routledge

Link to Published Version:

http://dx.doi.org/10.1080/07294360902725025 


\title{
Disciplining writing: the case for multi-disciplinary writing groups to support writing for publication by higher degree by research candidates in the humanities, arts and social sciences
}

\author{
Denise Cuthbert, Ceridwen Spark \& Eliza Burke
}

\begin{abstract}
This article addresses multi-disciplinary writing groups in supporting writing for publication for higher degree by research candidates in the Humanities, Arts and Social Sciences. Drawing on focus group discussions with postgraduate research students from the Faculty of Arts at Monash University in Australia who participated in the writing groups, it investigates the participants' perceptions of the multi-disciplinary nature of the groups and some of the benefits of sharing writing with fellow postgraduate research students from different fields of study. Discussing both the strengths and weaknesses of the multi-disciplinarity of the groups as identified by participants, the authors suggest that such groups can provide a forum for postgraduates to develop their 'professional' academic identity and develop their writing beyond the context of their theses and can have some unexpected benefits to participants' sense of themselves as disciplinary proponents. The multi-disciplinary context is thus considered as providing a level playing field in which postgraduates may approach the writing process as a shared methodology, encompassing a suite of specialised but generic skills that cross-disciplinary boundaries.
\end{abstract}

Keywords: doctoral education; generic skills; multi-disciplinarity; research publications; writing groups

\section{Introduction}

This paper reports on research with doctoral candidates in Humanities, Arts and Social Sciences (HASS) disciplines who participated in a program in which they worked in facilitated multi-disciplinary groups throughout 2005, gaining skills in the development of research papers for publication. We report briefly on the findings of the research with respect to the program's outcomes (for a full account of the program, see Cuthbert and Spark, 2008). In particular, we focus on reporting the students' reflections on working on writing in a multidisciplinary setting. The participants' views on multi-disciplinarity provide insights into the broader question of where the emphases in postgraduate research education should lie. That is, the discussion around the question of whether doctoral education provides (or should provide) highly specialised knowledge, which is most frequently equated with 'disciplinary' knowledge; or whether the objective of doctoral education is, or should be, something broader, encompassing more generic, professional or transferable skills (Breslow, 2006; Chan, 2006; Kwiram, 2006; Richardson, 2006). The importance of this issue to postgraduate 
education providers, educational researchers and, it would now appear, academics speaking from within their respective disciplines, is evident in a growing body of literature (Boud \& Tennant, 2006) and highlighted in the publication in 2006 of a collection of 21 essays, Envisioning the future of doctoral education (Golde \& Walker, 2006) in which the question of the doctorate and 'stewardship of the disciplines' is addressed from disciplinary viewpoints. As acknowledged by many contributors to this volume and other commentators, the rapidly changing context of higher education and changes in the post-doctoral employment prospects of postgraduates make these questions more pressing than ever before (Boud \& Tennant, 2006; Chan, 2006; Graff, 2006; Stimpson, 2006).

The tension between different views of what postgraduate research education can, or should, be is heightened by features of the contemporary university and the regulatory and funding contexts of higher education. The first is the increasing pressure faced by academics and students alike for greater productivity and accountability, which is detailed here with reference to the Australian context. This drive for accountability increasingly includes expectations on the part of government and funding agencies for doctoral programs to deliver researchers who are able to contribute to 'innovation and economic development' (Boud \& Tennant, 2006, p. 293). Another feature of the contemporary university is the impact of mass postgraduate research education, which has seen the production of unprecedented numbers of higher degree by research theses (Evans, Murphy, Pearson, \& Tregenza, 2003), alongside a constrained academic labour market, particularly in some HASS disciplines. If, in the Australian context, more doctoral graduates pursue careers outside the university, should the doctorate be re-styled to meet these more diverse needs (Boud \& Tennant, 2006)?

In recent decades, Australian higher education has been characterised by intensified competitiveness for research and other funding and mounting pressure on academics to ‘publish or perish’ (McGrail, Rickard, \& Jones, 2006). This pressured environment has been shaped by the introduction of quantifiable measures, to which funding is linked, for assessing research productivity. These include the introduction in 1995 of the Research Quantum Scheme under which publications in approved categories are audited through the Higher Education Research Data Collection and funding allocated on this basis. This scheme was subsumed into the Institutional Grants Scheme as part of the Research Training Scheme in 2001 (Department of Education, Science and Training, 2006) and resulted in the de-valuing of publications in relation to other indicators of research productivity such as Higher Degree 
by Research (HDR) completions and load; and grants income. These quantitative measures of research productivity are now set to give way to more qualitative measures in the form of the Excellence in Research for Australia initiative, announced by the incoming federal Minister for Innovation, Hon. Kim Carr, in early 2008, by which the quality of Australian research outputs, including publications, will be measured and assessed (Carr, 2008).

These measures have altered the context in which research is conducted by academics and raise questions about postgraduate training and the 'professionalisation' of postgraduate researchers. Where once the production of a thesis was the sole requirement for doctoral graduates developing an academic career, candidates now face an uncertain future without additional 'evidence' of expertise such as published papers, conference attendances and teaching experience on completion of their degrees. Although the thesis remains the major formal requirement for attaining a $\mathrm{PhD}$ in most HASS disciplines within Australia, the publication of refereed papers during candidature is fast becoming an expected part of graduating as a competitive researcher. Further, the introduction by most Australian universities of the $\mathrm{PhD}$ by publication (Sheely, 1996) has added further pressure for postgraduate programs to address the issue of skills in writing and publishing; as have the introduction of different types of doctorates many of which comprise folios of published and unpublished papers (Maxwell \& Kupczyk-Romanczuk, forthcoming; Park, 2007). Doctoral training is no longer simply a process of 'turning novices into experts' (Leverenz, 2001, p. 58), but appears to be increasingly one of turning novices into published experts.

Meeting these demands means that postgraduate training must now attend to developing professional skills amongst postgraduates not strictly associated with thesis writing. Skills relating to the processes of writing articles for refereed journals, submitting papers for review and responding to feedback are now considered significant generic skills that should have some place in research training programs (Chan, 2006; Richardson, 2006). These skills are generic, in that they cross the disciplinary boundaries within which a $\mathrm{PhD}$ thesis is produced, and pertain, with variations in convention, to the academic research endeavour generally. While the pressure on postgraduates to compete in the 'professional' world of academic publication is seen by some commentators as a potentially 'deforming' factor in postgraduate research education which can lead to 'intellectual shallowness' and a preoccupation amongst students with self-marketing (Guillory, 1996), it is clear that the PhD qualification is now seen to signify an 'expertise' beyond the traditional requirement of making an 'original 
contribution to knowledge' generally assessed within a disciplinary framework. The extent to which publication or teaching skills should be developed as part of the postgraduate education and within the supervisory relationship has been the subject of some discussion in pedagogical research (Richardson, 2006). Within postgraduate research education, we are still in the early stages of understanding the respective merits of the various means, such as writing groups, by which postgraduate research students may acquire these skills.

\section{Writing groups}

Generally academic writing groups have been approached as a way of developing research potential and supporting writing for publication amongst academic staff (Boud \& Lee, 1999; Page-Adams, Cheng, Gogineni, \& Shen, 1995). Research on the potential role of peer-based writing groups or publication syndicates for postgraduates, however, is limited to a few examples of writing groups conducted through university writing centres (Leverenz, 2001). This may be because there are few writing for publication programs specifically for postgraduates: even universities with dedicated writing centres comment that postgraduates receive 'little assistance' to learn new ways of writing (Garbus, 2005, p. 172). Though university managers have begun to see 'the need for the development of staff in the research role in the light of growth of higher education and changes to the sector in many countries' (Lee \& Boud, 2003, p. 187), the evidence suggests that, overall, this vision has not yet been extended to include postgraduates. This is not to say that efforts have not been made to establish writing groups or other programs to assist postgraduate research candidates develop writing for publication, but simply that this work has not, with the few exceptions cited here, been documented.

There is a relative gap in the literature on writing for publication groups for postgraduate research candidates, as distinct from writing for publication initiatives for academic staff (McGrail et al., 2006; Murray \& Mackay, 1998); pedagogies for development of thesis writing skills for research students (Kamler \& Thomson, 2006); and specialist research writing skills for international or second-language research students (Swales \& Feake, 2004). Although, notably, the pedagogy outlined by Swales and Feake (2004) anticipates some aspects of the Graduate Researchers in Print (GRiP) program in that it employs a multidisciplinary approach with a genre analysis method. Nonetheless, the relative gap in the literature is surprising given the findings from the one article on postgraduate writing for publication groups that seven of the eight member group wrote, submitted or published a 
paper during their membership compared to only two of ten of the non-member group (PageAdams et al., 1995, p. 405). Indeed, the article goes further, suggesting that 'new faculty members who learned to balance writing, teaching and collegiality early in their academic careers had relatively high levels of publication productivity’ (p. 406). This article constitutes an important step in considering the appropriate way to enhance the publication potential of HASS postgraduate research students. Further, by focusing discussion on multi-disciplinarity, it further makes a contribution to the sometimes polarised field of opinion on this subject and its relationship to postgraduate training and professional development, and debates on the nature of doctoral education itself. Before embarking on this discussion, however, it is necessary to consider how multi-disciplinarity has been considered in the limited literature on writing groups.

\section{Multi-disciplinarity in writing groups: strength or weakness?}

Positive outcomes of writing groups occur whether or not they are run as single or multidisciplinary groups. The evidence indicates that there is more to suggest that a mix of disciplines is a strength rather than a weakness of writing groups, though there is nothing to suggest single-discipline groups are perceived as problematic. Morss and Murray (2001) argue that a multi-disciplinary writing for publication programme 'offered the best solution because it was an incremental, eclectic approach' (p. 38). Boud and Lee’s (1999) support for multi-disciplinary groups is unequivocal: [t]he mixture of staff from different locations and disciplinary locations, far from being a limitation proved to be an important feature of the group. ... At first, members of the group expressed ... doubts about their ability to contribute much to those in other academic areas. As the group progressed, the commonalities of interest in constructing a paper, of understanding the journal publishing process and sharing drafts led to a realisation, shocking to some, that they really were colleagues engaged in the same business as each other with common concerns and desires. (p. 5).

The 'commonalities of interest in constructing a paper' are highlighted by findings from research with a postgraduate writing group made up of social work doctoral students at Washington University (Page-Adams et al., 1995). As social work students, this group might be considered to be working in the same area. Nevertheless, these students suggest that 'members were often reviewing work outside their own areas of interest' and that this enhanced 'the demand for clear and complete conceptualisation' (Page-Adams et al., 1995, p. 404). Pointing to the value of a focus on the 'writerly' aspects of a paper, such as clarity of 
argument, structure and the quality of the prose, their reflections suggest that an emphasis on discipline-specific content may obscure the overall view of a piece and result in unhelpful feedback from writing group participants. As Garbus (2005) points out, in addition to requiring the students 'to write in a jargon-free and clear manner so that group members in other fields could understand their writing', multi-disciplinary groups eliminate [or at least minimise] competition' (p. 172). This, she argues, is the reason why a cohort of Missouri postgraduate students in writing center-led dissertation groups preferred to be in groups with members of other disciplines’ (p. 172).

Galligan et al. (2003) set up cross-disciplinary writing groups so that group members might have 'the benefit of a broad range of skills and experience' (p. 4). These authors argue this enhanced collegial relations became one of the group’s main strengths. Participants appreciated the 'stimulating mix of disciplines'. Leverenz also notes that combining disciplines helped create an objective environment, away from the pressures of disciplinary expertise, which enabled writers 'to get involved in generating ideas about writing' and increase their confidence 'to translate and interpret academic language and academic culture' (2001, p. 53). In their study of two academic writing groups at an Australian university, Boud and Lee (1999) suggest the strength of the groups lies in their capacity to foreground knowledge about writing before disciplinary knowledge, which helps to position 'participants as active scholarly writers within a peer-learning framework' (p. 9) and 'demystify the processes of scholarly writing and publication' (p. 2).

Discussion about the perceived or anticipated merits and pitfalls of multidisciplinary writing groups is central to the analysis of the qualitative material collected for this study. Overall, the perceived negative effects of multi-disciplinarity are limited to participants' experience of reading papers from different disciplines and offering what they felt to be 'appropriate' feedback. On this point, it should be noted, as documented in other research, that initial feelings of lack of confidence in their ability to provide critical feedback on the writing of others is common among participants in writing groups, irrespective of their disciplinary or multi-disciplinary composition (see for example, Lee \& Boud, 2003). Despite this initial lack of confidence, confirming findings from other research into writing groups, the majority of participants reported that the process of providing feedback had positive effects on the process of writing. Our data shows that participants link the multi-disciplinarity of the program to positive outcomes beyond writing, including self-confidence, a sense of agency 
and 'know how' for writing, to actually producing published papers. Further, for some participants, the multi-disciplinarity of the program also worked directly to enhance their sense of themselves as disciplinary exponents. It appears, then, that the multi-disciplinary approach might provide for participants a level playing field for the development of skills, self-confidence, honing a sense of expertise in writing and publication and, as we argue below, confidence in themselves as disciplinary proponents. Before embarking on an analysis of this material, however, it is necessary to describe the GRiP program and research methodology.

\section{GRiP: description of the program and research methodology}

The GRiP program was initiated and established in 2005 to support higher degree research candidates in a broad and diverse Faculty of Arts in developing scholarly publications. The program was designed to meet several objectives, which included boosting the faculty's overall rate of publication, but the primary aims remained student-focused. Reflecting what is known in the bibliometric literature (Stokes \& Harley, 1989) about co-publication rates in HASS disciplines as compared with many science and technology disciplines, the rate at which Arts candidates published and co-published during candidature was significantly lower than the rate of publication and co-publication in faculties such as science and engineering. It appears that the individualistic writing and publication culture among staff in the faculty operates as an impediment to many research candidates 'learning the ropes' of publication directly from their supervisors. For example, 2004 Research Quantum data showed that only 7\% of the total Arts HDR cohort authored or co-authored Department of Education Science and Training reportable publications in that period, compared with over $25 \%$ in some other discipline areas. In contrast to other disciplines, such as the sciences and technologies, where co-publication amongst teams of researchers is the norm and postgraduate students are inducted into team publications as junior contributing authors alongside their supervisors (Stokes \& Harley, 1989), HASS candidates generally lack this 'hands on', direct induction into research publication. As a result, the process of writing for publication was shrouded in mystery and generated feelings of anxiety in postgraduate students (Cuthbert \& Spark, 2008). The GRiP program was designed to remedy this by providing a facilitated and peer-supported structure in which the skills in research publication could be taught, work-shopped and refined by participants as an adjunct to their discipline-based research supervision. 
The program, as it ran in 2005, consisted of four writing groups made up of 28 participants, including 26 research candidates who were writing their masters and PhDs in the faculty. Participants were predominantly first-language speakers of English, although there were several for whom English was a second or third language. The groups also included two recently completed but hitherto unpublished $\mathrm{PhD}$ graduates. Each of the four groups of between six and nine people met once a month for two hours in a seminar room within the faculty.

The groups met nine times in 2005. The program employed peer-support and review in a workshop setting. Students were required to draft an article or chapter to be read and discussed by the group and to read the drafts of other members of their group. The time commitment for GRiP participants was attendance at one two-hour workshop per month and the time required to draft material and read the work of other group members. Over the year, the facilitator also ran sessions on various aspects of publishing, including: identifying appropriate journals, preparing submissions, responding to reviewers' reports, writing book proposals, turning theses into books and writing for the non-academic media.

Graduate Researchers in Print participants came from various disciplines in the Arts Faculty. The decision to run multi- rather than single-discipline groups was based partly on practical concerns, including the diverse backgrounds of participants - for instance there was only one person from Italian Studies, compared with ten from the predominantly social science disciplines housed within the School of Political and Social Inquiry. It was, however, also strongly influenced by the expectations of the GRiP coordinator and facilitator that multidisciplinary groups would encourage GRiP participants to focus primarily on writing, rather than on the discipline-specific details of content. In addition, it was felt that supervisors would (or should) be filling the role of 'expert' content readers. These issues are taken up in the next section in which the findings about the multi-disciplinary nature of the program are discussed.

The data for this study were collected in 2005 by means of four 20-40 minute focus group discussions conducted by the group facilitator, Ceridwen Spark, at the final session of each GRiP group. The focus group method was selected as it was a natural extension of the productive dynamic that had developed throughout the year. While having the facilitator conduct the discussion involved the risk that this would skew responses, we felt that a 
researcher who had not taken part in group meetings would be unlikely to have sufficient insight into group learning and process to conduct meaningful group discussions on the subjects we wished to consider. Nevertheless, because it is possible that the group facilitator, by acting as researcher, may have skewed responses, we see the present article as an introduction to the topics addressed herein and recommend that further research be conducted into the outcomes of multidisciplinary writing groups.

The focus groups comprised 20 participants who consented to participate in the research and were present at the final meeting. During the focus group discussions, participants responded to questions designed to promote discussion around the theme of writing for publication and the extent to which GRiP had facilitated this process. These included questions about publishing, such as how they felt about it prior to, and after, participating in the GRiP program. Participants were asked to discuss what they found most helpful and most difficult about their involvement in the program, including difficulties or barriers they had encountered in terms of the peer-review process. Also, they were asked whether they would recommend others participate in GRiP and whether their perception of their own research potential had changed as a result of participation.

Discussions were tape-recorded and transcribed. The transcripts were coded and analysed by the authors using the qualitative data analysis program NVivo with particular attention paid to recurring themes in the data. For illustrative purposes, portions of focus group discussion are presented below. In the following analysis, all participants, with one exception, have been assigned pseudonyms by the authors to ensure anonymity. The exception is Marina Cominos, who is quoted below with her consent from a conference presentation in December 2006 (Cuthbert, Spark, \& Cominos, 2006).

\section{Findings}

Participants were positive about their involvement in the program. For instance, none of the program participants who took part in the evaluations expressed negative experiences in submitting their own work to the process of peer review. This is a notable finding given the intimate link between writers and their work, such that criticism of one's writing may be felt as 'an attack on the self' (Gere, 1987, p. 103). The program had positive 'hard' outcomes (Morss \& Murray, 2001) as revealed by a survey in the last sessions of each group in December 2005. By this stage, 19/26 GRiP participants had drafted an article for eventual 
publication in a referred journal; 14/26 participants had submitted an article for scholarly review for publication, with a total of 17 articles submitted; 4/26 had journal articles accepted (all others were waiting on reviewers' reports); 5/26 had commenced a draft of a chapter for publication in an edited book collection; and 6/26 had conference papers accepted for publication.

Graduate Researchers in Print participants reported other benefits or 'soft outcomes' (Morss \& Murray, 2001) including: a sense of being 'supported' instead of 'pressured' to publish; confidence that they knew how to get published; a sense of community with other postgraduate students; and increased awareness about what makes a good article. Analysis of the data on participants' attitudes to the multi-disciplinary composition of the writing group revealed attitudes divided between the 'fors and againsts', to use the words of one participant, Siobhoan. Overall, however, participants felt that the advantages of being in multidisciplinary groups outweighed the disadvantages. The main reason participants gave for their positive response to GRiP's multi-disciplinary structure was that they felt that the multidisciplinarity facilitated the objective of the groups by enabling a focus on improving writing. Glenn, in an indicative comment, highlights the values of having someone from outside the discipline bring a broader perspective, saying that it was good to have:

somebody read it who's not so ... buried within that discipline is a good thing because when you have things like, 'I don’t think you've given enough background detail here', you might not be aware of that yourself because you're so familiar with the arguments that having somebody else point that out to you can help, it can expose, maybe, your own blind spots or the blind spots of that discipline to a level of scrutiny so ... stuff like, 'Look, this needs to be explained better to general audience because I'm a general audience and I don't get it'.

This was supported by Georgina:

I think it's really good having people who are from similar backgrounds and really different, because when people ask you questions that seem quite basic, it's just really good for you to try to explain something that you think is obvious and then you think 'Oh actually, how do I explain that?' 
Supporting Gere's finding (1987), Sarah added that the process of commenting on others' work enhanced her capacity to critique her own work:

I feel like I learnt a lot about actually approaching a piece of work and marking it in a way. Like I actually feel like I've come out of this and being able to, when I write my own stuff, with much greater, like, ability just to go through and be ... really be able to see where I’m not making sense ... I really appreciated that practice.

The freedom to critique, and indeed praise, others was also felt to be enhanced by the multidisciplinarity of the groups. In addition to supporting the finding that reduced competitiveness is a beneficial feature of multi-disciplinary writing groups (see Garbus, 2005), the following comments go further, indicating a positive link between multidisciplinarity and group members’ willingness to encourage others:

Sometimes it can be a little bit competitive within your own discipline, like I often don’t enjoy talking with history students because everyone’s got their own agenda, that's life, and it is competitive. Whereas this hasn't got to me like that - we're not working alongside each other, it’s not really overlapped so you can be a bit more generous. (Emma)

For Nick, a sense of validation of the importance of his work came from hearing the responses of a multi-disciplinary audience:

And, I think, seeing an audience responding to your work from a different perspective is actually quite reassuring, it's quite, um, it's quite a nice feeling as well, when other people from other disciplines can actually see the value, or the merit, of your work. It's actually quite a nice feeling, even if, you know, they can see, it interests them, not necessarily that they think it's a great article but that they see that it's worth pursuing. I think that's why it's good.

Another dimension of this willingness to be 'a bit more generous' (Emma) than they might be in their disciplinary settings appears to have direct, positive consequences on the participants' self-perceptions as proponents of their disciplines. Marina Cominos, in a presentation on the GRiP program in December 2006 (Cuthbert et al., 2006), pointed to the way the multi- 
disciplinary collegiality, whereby individual participants may be the only representatives from their disciplines in the group, fostered disciplinary confidence and a concomitant sense of authority. This sense of confidence and the opportunity to represent their disciplines, Marina suggested, are attributes that participants, as novice researchers and junior disciplinary proponents, struggled to attain in the context of their schools, alongside members of the academic staff and other postgraduate researchers in the discipline.

For Marina, GRiP provided an opportunity to develop an 'authoritative voice’ in speaking and, importantly, writing - on her speciality, political theory, within a group with only general knowledge about the discipline and its key debates. As Marina argues, GRiP enabled participants to 'try out' the role of disciplinary specialist in a supportive, rather than a competitive, context. It enabled her, to 'develop my own voice' as a political theorist in discussions with others who had less knowledge than she did about the field. For Marina, this had a positive impact on her sense of herself as doctoral candidate and thesis writer. The confidence and growing sense of authority promoted within the multi-disciplinary context of GRiP have carried over to her sense of herself as 'political theorist' in relation to her thesis.

Contrasting with these positive comments on multi-disciplinarity, GRiP participants reported the view that single discipline groups might be intimidating and likely to result in members becoming distracted. One example was the potential for different theoretical positions which inevitably arises within discipline-based discussions to derail discussions, and to inhibit members from '[speaking] out':

It's less intimidating, I suppose, because if you have people ... who are studying the same thing they might have different theories ... so you probably tend to feel a bit, you know, not brave enough to speak out about your research. After all, it's your project. So having people from different backgrounds, in a way, gives you some sort of sense of 'This is my project, I'm introducing to you guys, what do you think?' You know what I mean? (Jane)

Jane's comments confirm the view of Marina regarding the confidence and sense of ownership GRiP encouraged participants to have in their projects and their disciplinary expertise: 'This is my project, I’m introducing to you guys ...' (Jane). 
The GRiP groups' capacity to focus on the writing and avoid detail that is not related to writing and readability is also commented on by Sarah:

Yeah it does take away that, when you're doing it in terms of that, actually just the writing of it, it does take away that personal thing that could sort of, you know, get people’s backs up, unless you're actually saying 'I actually agree with your point.' Getting into the nitty-gritty of [the writing].

In a similar vein, Glenn speculates that the divisions within disciplines and the tendency for some disciplinary exponents to take up 'fundamentally opposed' positions on issues could lead to endless disputation on those issues, leaving the question of the quality of the writing as writing unaddressed:

Whether having everybody from the same discipline would be a good idea I don't think so, I think that would ... be too insular, either too much ... of a similar opinion or you'd find people within that discipline who were on fundamentally opposed sides of that discipline and would end up just arguing about those issues all day, you wouldn’t get anything done.

In addition to the above, GRiP participants seemed generally stimulated by the mix of disciplines, a finding also noted in previous research (Boud \& Lee, 1999; Lee \& Boud, 2003). Georgina, in a representative comment, notes:

It's great to get people's feedback who are from very different [disciplines], who are doing really different work. And it’s great to read other people's work, who are doing really different things. I love reading other people’s work, and yeah, talking about it. I think that's really mutually beneficial.

John's comments support this finding: 'I would recommend the GRiP ... experience, I think, for the value of hearing from people in other disciplines. That was very important.' The positive effects of sharing work here relate to debunking the 'the commonplace received fantasy of writing as a solitary activity’ (Boud \& Lee, 1999, p. 2) and engaging with the processes of drafting and critiquing as normalized or 'everyday' activities of the academic. The groups provided a forum for developing a cross-disciplinary language for talking about 
writing or an 'exploratory discourse' for discussing finished and unfinished texts (Gere, 1987, p. 73). Above all, the multidisciplinary context of the groups allowed for writing to be foregrounded as a practice involving collaboration between a writer and a reader long before its final publication as text. The specialized skills of writing for an audience, as distinct from the specialist skills of working within a given disciplinary framework, were foregrounded through the GRiP process and shared between participants from many disciplinary backgrounds.

Participants were unanimous that the process of having their work peer-reviewed was positive and helpful. The multi-disciplinarity of the groups appears to have actively assisted this outcome by allowing for a non-competitive, supportive environment and a clear focus on writing as writing. The findings on the relationship between multidisciplinarity and the benefits for participants acting as reviewers of the written work of others are not as clear, with several participants expressing some ambivalence on this aspect of the program. The main reason participants cited for this difficulty was their lack of confidence in their capacity to provide helpful critique on work from another discipline. Maria, for example, remarked: 'the hardest thing for me was sometimes reading other people's stuff because I find I can't really contribute any substantial comments because I'm just ... so far removed from that area and that topic and that field or discipline'. To some extent, this was supported by Glenn who sometimes wondered: 'How can I comment on this, it's not a discipline I'm from, maybe I'm ... not familiar with the ... way that discipline is conducted so I'm missing something.'

Doubt among group members about the capacity to provide helpful feedback to people from other disciplines is also identified by Lee and Boud (2003) in their research. Nevertheless, they conclude that this doubt was assuaged as participants realised their commonality as writers. It is fair to speculate that this may have been the case with the majority of GRiP participants. Only three of the 20 focus group participants mentioned multidisciplinarity as something that decreased their sense of confidence about reading other group members' work and, of these, two were ultimately equivocal about the multidisciplinarity of the groups with Siobhan, for example, discussing the 'fors and againsts' and Glenn saying that this feature 'was a strength and a weakness'.

One GRiP participant left the program early in the year because she felt she would not gain anything from being in a multi-disciplinary group. This may reflect certain self-selectiveness 
for inclusion and ongoing participation in GRiP whereby students elected to participate on the basis of openness to multi-disciplinarity in the first place. It is also the case, however, that group members found critiquing the work of others - regardless of disciplinary considerations - to be one of the challenges of the program and that this challenge exists irrespective of the disciplinary or multi-disciplinary context in which the critique is called for. Karen, for example, cited 'critiquing people when they're in the room' as the aspect of GRiP she found hardest and Sarah remarked on her own 'lack of confidence [about] ... being able to write any constructive criticism'. At the same time, also confirming the findings of Lee and Boud (2003), GRiP participants revealed that they overcame the challenges in mounting a critique of the writing of others and actively benefited from the process. According to Sarah, quoted above, critically reviewing another person's writing makes one more reflective as a writer.

\section{Conclusion: placing the findings in the broader context of debates on doctoral education}

Richardson, from the discipline of education, calls for writing for publication programs along with generic and professional skills programs to assist doctoral candidates develop what she

calls ‘practical knowledge' which should be taught as part of doctoral programs (Richardson, 2006, pp. 265-266). Beyond HASS disciplines, in the context of doctoral education in mathematics, Chan (2006) advocates reform of doctoral education to incorporate explicit training in 'professional skills' including 'training in mathematical writing [and] proposal writing' (p. 103) and 'the more refined skills of scientific writing, interacting with editors, preparing peer-review evaluations’ (p. 109) (see also Breslow, 2006; Kwiram, 2006). While from different disciplines, these commentators write squarely within their respective disciplinary frameworks and call for the incorporation within those frameworks, or alongside them, of training of a more generic kind to enhance outcomes for postgraduate students and for their respective disciplines.

Findings from research with GRiP participants suggest one way forward in balancing the seemingly competing demands for greater levels of specialisation (or depth) in doctoral research with calls, such as those above, for the incorporation into doctoral education of training in a range of generic and professional skills, by way of providing breadth to doctoral education. Multi-disciplinary groups may offer a valuable addition to discipline-based doctoral education. Findings from research with the GRiP program show multi-disciplinary writing groups in the context of HASS are not seen by postgraduate research students as 
antithetical to, or compromising of, disciplinary specialisation. Rather, GRiP participants experienced the multidisciplinary groups as complementing their discipline-based research and productive of other kinds of specialist skills not currently provided within most disciplinary programs.

\section{Acknowledgements}

The authors are grateful to staff in the Arts Research Graduate School, Monash University, for their assistance in the conduct of this research.

\section{References}

Boud, D., \& Tennant, M. (2006). Putting doctoral education to work: Challenges to academic practice. Higher Education Research \& Development, 25(3), 293-306.

Boud, D., \& Lee, A. (1999). Promoting research development through writing groups. Paper presented at the Australian Association for Research in Education Conference Melbourne, Australia. Retrieved December 26, 2006, from http://www.aare.edu.au

Breslow, R. (2006). Developing breadth and depth of knowledge: The doctorate in chemistry. In C.M. Golde, \& G.E. Walker (Eds.), Envisioning the future of doctoral education: Preparing stewards of the disciplines. Carnegie essays on the doctorate (pp. 167186). San Francisco: Jossey-Bass.

Carr, K. (2008). New ERA for research quality: Announcement of excellence in research for Australia initiative. Retrieved July 28, 2008, from http://www.arc.gov.au/media/releases/media_26feb08.htm

Cuthbert, D., \& Spark, C. (2008). Getting a GRiP: Examining the outcomes of a pilot program to support Graduate Research Students in Writing for Publication. Studies in Higher Education, 33(1), 77-88.

Cuthbert, D., Spark, C., \& Cominos, M. (2006, December). The GRiP (Graduate Researchers in Print) program: Pedagogy and practice in a facilitated and peer-supported program. Presentation at the Vice-Chancellor's Showcase of Teaching Excellence, Monash University. Retrieved December 26, 2006, from http://www.monash.edu.au/teaching/vcshowcase/program/showcase-early.html

Chan, T. (2006). A time for change? The mathematics doctorate. In C.M. Golde \& G.E. Walker, (Eds.), Envisioning the future of doctoral education: Preparing stewards of the disciplines. Carnegie essays on the doctorate (pp. 120-134). San Francisco: Jossey-Bass. 
Department of Education, Science and Training. (2006). The research training scheme: 2006 guidelines. Retrieved December 26, 2006, from

http://www.dest.gov.au/sectors/research_sector/programmes_funding/programme_cat egories/professional_skills/research_training_scheme.htm

Evans, T., Murphy, P., Pearson, M., \& Tregenza, K. (2003). A decadic review of PhDs in Australia. Unpublished paper presented at the Australian Association for Research in Education Conference, Auckland NZ.

Galligan, L., Cretchley, P., George, L., McDonald, K., McDonald, J., \& Rankin, J. (2003). Evolution and emerging trends of university writing groups. Queensland Journal of Educational Research, 19(1), 28-41.

Garbus, J. (2005). Tutoring graduate students in the writing center. Academic Exchange Quarterly, 9(3), 172-174.

Gere, A.R. (1987). Writing groups: History, theory and implications. Carbondale and Edwardsville, IL: Southern Illinois University Press.

Golde, C.M., \& Walker, G.E. (Eds.). (2006). Envisioning the future of doctoral education: Preparing the stewards of the disciplines. Carnegie essays on the doctorate. San Francisco: Jossey-Bass.

Graff, G. (2006). Towards a new consensus: The PhD in English. In C.M. Golde \& G.E. Walker (Eds.), Envisioning the future of doctoral education: Preparing stewards of the disciplines. Carnegie essays on the doctorate (pp. 370-389). San Francisco, Jossey-Bass.

Guillory, J. (1996). Preprofessionalism: What graduate students want. Association of Departments of English Bulletin, 113(Spring), 4-8.

Kamler, B., \& Thomson, P. (2006). Helping doctoral students write: Pedagogies for supervision. London and New York: Routledge.

Kwiram, A.L. (2006). Time for reform? In C.M. Golde \& G.E. Walker (Eds.), Envisioning the future of doctoral education: Preparing stewards of the disciplines. Carnegie essays on the doctorate (pp. 135-140). San Francisco, Jossey-Bass.

Lee, A., \& Boud, D. (2003). Writing groups, change and academic identity: Research development as local practice. Studies in Higher Education, 28(2), 187-200.

Leverenz, C. (2001). Graduate students in the writing center: Confronting the cult of nonexpertise. In J. Nelson, \& K. Everz (Eds.), The politics of writing centers (pp. 5061). Portsmouth, NH: Heninemann/Boynton-Cook. 
Maxwell, T.M., \& Kupczyk-Romanczuk, G. (forthcoming). The professional doctorate: Defining the portfolio as a legitimate alternative to the dissertation. Innovations in Education and Teaching International.

McGrail, M., Rickard, C., \& Jones, R. (2006). Publish or perish: A systematic review of interventions to increase academic publication rates. Higher Education Research \& Development, 25(1), 19-35.

Morss, K., \& Murray, R. (2001). Researching academic writing within a structured program: Insights and outcomes. Studies in Higher Education, 26(1), 35-52.

Murray, R., \& Mackay, G. (1998). Supporting academic development in public output: Reflections and propositions. International Journal for Academic Development, 3(1), 54-63.

Page-Adams, D., Cheng, L., Gogineni, A., \& Shen, C. (1995). Establishing a group to encourage writing for publication among doctoral students. Journal of Social Work Education, 31(3), 402-407.

Park, C. (2007). Redefining the doctorate. Discussion Paper, The Higher Education Academy, UK. Retrieved 10 December, 2007, from http://www.heacademy.ac.uk/assets/York/documents/ourwork/research/redefining the_doctorate.pdf

Richardson, V. (2006). Stewards of a field, stewards of a discipline: The doctorate in education. In C.M. Golde \& G.E. Walker (Eds.), Envisioning the future of doctoral education: Preparing stewards of the disciplines. Carnegie essays on the doctorate (pp. 251-267). San Francisco: Jossey-Bass.

Sheely, S. (1996, July). A degree by any other name: An historical reflection on traditional and non-traditional PhD programs. Proceedings of the HERDSA Conference, Perth, Western Australia. Retrieved December 26, 2006, from http://www.herdsa.org.au/confs/1996/sheely2.html

Stimpson, C. (2006). Words and responsibilities: Graduate education in the humanities. In C.M. Golde \& G.E. Walker (Eds.), Envisioning the future of doctoral education: Preparing stewards of the disciplines. Carnegie essays on the doctorate (pp. 390418). San Francisco, Jossey-Bass.

Stokes, T.D., \& Harley, J.A. (1989). Co-authorship, social structure and influence within specialities. Social Studies of Science, 19(1), 101-123.

Swales, J.M., \& Feake, C.B. (2004). Academic writing for graduate students: Essential tasks and skills. Ann Arbor, MI: University of Michigan Press. 